\title{
Linfoma subcutâneo de células T paniculite-símile *
}

\author{
Subcutaneous panniculitis-like T-cell lymphoma
}

\author{
Renato Soriani Paschoal ${ }^{1}$ \\ Darlene Arruda ${ }^{3}$ \\ Cacilda da Silva Souza
}

\author{
Renata Nahas Cardilli ${ }^{2}$ \\ Belinda Pinto Simões ${ }^{4}$
}

\begin{abstract}
Resumo: Linfoma subcutâneo de células T paniculite-símile foi recentemente reconhecido como entidade clínico-patológica. Paciente do sexo feminino, 17 anos, relatou nodosidades eritêmato-violáceas e depressões nos membros e abdome há três anos e discreta perda ponderal, sem outros sintomas gerais. Adenomegalia, visceromegalias e infiltração da medula óssea estavam ausentes, e a histopatologia da pele mostrou densa infiltração de linfócitos atípicos CD3/CD8 no subcutâneo. A quimioterapia interrompeu o surgimento de novas lesões com remissão das pré-existentes no seguimento de oito meses. Aspectos imunofenotípicos e moleculares são relevantes para elucidação diagnóstica e avaliação do prognóstico.

Palavras-chave: Imunoistoquímica; Linfoma não Hodgkin; Paniculite
\end{abstract}

\begin{abstract}
Subcutaneous panniculitis-like T-cell lymphoma is extremely rare and has recently been recognized as a clinicopathological entity. Young female, 17 years old, has complained of subcutaneous nodules and plaques in the limbs and abdomen for three years, accompanied of mild weight loss without other constitutional symptoms. Nodal, visceral and bone marrow involvement was absent, and subcutaneous $\mathrm{CD} 3 / \mathrm{CD} 8$ atypical lymphocyte infiltration was observed in the skin sample. Chemotherapy interrupted the onset of new lesions and led to remission in the 8-month follow-up. Immunophenotypic and molecular aspects were relevant to the diagnosis and as prognosis makers.

Keywords: Immunohistochemistry; Lymphoma, non-Hodgkin; Panniculitis
\end{abstract}

\section{INTRODUÇÃO}

Os linfomas cutâneos primários de célula $\mathrm{T}$ (LCCT) compreendem um grupo de linfomas nãoHodgkin (LNH) com características clínicas e biológicas heterogêneas. São definidos como proliferação clonal maligna de linfócitos $\mathrm{T}$ ou células natural killer (NK) residentes na pele. ${ }^{1-4} \mathrm{~A}$ atual classificação da OMS para os LCCT lista 13 entidades. Micose fungoide e suas variações, síndrome de Sézary, linfoma cutâneo de grandes células anaplásicas e papulose linfomatoide representam aproximadamente $95 \%$ dos LCCT. ${ }^{1,4}$
O linfoma subcutâneo de células T paniculitesímile (LSCTPS) é um tipo incomum de LCCT que foi reconhecido como entidade clínico-patológica apenas em 1991. Até 2003, menos de 200 casos haviam sido relatados na literatura de língua inglesa. A neoplasia compromete adultos e crianças, e igualmente ambos os sexos. ${ }^{5}$ Clinicamente, caracteriza-se por nódulos ou placas eritematosas e infiltradas, raramente ulceradas, solitárias ou múltiplas, envolvendo principalmente as extremidades, ou generalizadas, comprometendo

\footnotetext{
Recebido em 22.08.2008.

Aprovado pelo Conselho Editorial e aceito para publicação em 30.10.2008

* Trabalho realizado no ambulatório de dermatologia oncológica do Hospital das Clínicas da Faculdade de Medicina de Ribeirão Preto da Universidade de São Paulo (FMRP-USP) - Ribeirão Preto (SP), Brasil.

Conflito de interesse: Nenhum / Conflict of interest: None

Suporte financeiro: / Financial funding: Fundação de Apoio ao Ensino, Pesquisa e Assistência do Hospital das Clínicas da Faculdade de Medicina de Ribeirão Preto - Universidade de São Paulo.

Médico residente da Divisão de Dermatologia do Hospital das Clínicas de Ribeirão Preto da Faculdade de Medicina de Ribeirão Preto da Universidade de São Paulo - Ribeirão Preto (SP), Brasil.

Pós-graduanda do Departamento de Clínica Médica e médica assistente da Divisão de Dermatologia do Hospital das Clínicas da Faculdade de Medicina de Ribeirão Preto da Universidade de São Paulo - Ribeirão Preto (SP), Brasil.

In memoriam. Médica assistente do Serviço de Patologia do Hospital das Clínicas da Faculdade de Medicina de Ribeirão Preto da Universidade de São PauloRibeirão Preto (SP), Brasil

Professora doutora da Faculdade de Medicina de Ribeirão Preto da Universidade de São Paulo - Ribeirão Preto (SP), Brasil.

Professora doutora da Faculdade de Medicina de Ribeirão Preto da Universidade de São Paulo - Ribeirão Preto (SP), Brasil.

CC2009 by Anais Brasileiros de Dermatologia
} 
outras regiões. ${ }^{5}$ Manifestações sistêmicas como febre, perda de peso e fadiga podem estar presentes. O curso clínico pode ser prolongado, com ocasional regressão espontânea das lesões cutâneas, ou rapidamente progressivo e fatal, a despeito de agressiva quimioterapia. Nesse útimo quadro, o LSCTPS frequentemente é associado à síndrome hemofagocítica. ${ }^{5,6} \mathrm{~A}$ histopatologia é caracterizada por padrão paniculitesímile com envolvimento neoplásico do tecido subcutâneo. Essa infiltração do subcutâneo por células T pleomórficas e macrófagos benignos mimetiza paniculite lobular. Envolvimento da derme pode ser observado; no entanto, em geral a extensão da invasão dérmica é mínima, e o envolvimento da epiderme é raro. A proliferação mista de linfócitos atípicos é constituída, mais comumente, por grandes células de entremeio a médias e/ou pequenas células. As células malignas são predominantemente células $\mathrm{T}$ citotóxicas com expressão $\alpha \beta$ ou $\gamma \delta$ dos receptores das células T (TCR). ${ }^{6}$

As manifestações clínicas inespecíficas do LSCTPS podem dificultar e postergar o seu diagnóstico, para o qual o exame histopatológico e o imunoistoquímico são fundamentais. $\mathrm{O}$ eritema nodoso e as paniculites com distintas etiopatogenias são seus principais diagnósticos diferenciais. Sua raridade impõe ainda dificuldades na análise prognóstica e na decisão do tratamento mais adequado para cada paciente.

A seguir, relata-se o caso de paciente jovem do sexo feminino, destacando-se as dificuldades na elucidação diagnóstica, os aspectos dermatológicos, histopatológicos e imunoistoquímicos do LSCTPS e a remissão da doença quando submetida ao tratamento quimioterápico baseado nos derivados da antraciclina.

\section{RELATO DO CASO}

Paciente do sexo feminino, 17 anos, previamente hígida, com nodosidades eritematosas a violáceas associadas a depressões atróficas localizadas em membros e abdome (Figura 1 ) há três anos. Relatou investigação e terapêutica prévias para eritema nodoso sem sucesso. Referia perda ponderal não quantificada e negava febre e outros sintomas gerais. Ao exame físico, não foi observada adenomegalia, hepatoesplenomegalia e outras anormalidades. Seus exames laboratoriais - hemograma, urina I, função renal, enzimas hepáticas, fator antinúcleo (FAN) e eletroforese de proteínas - não evidenciaram alterações. As sorologias para hepatite $\mathrm{B}$, hepatite $\mathrm{C}$ e sífilis foram negativas, assim como as baciloscopias e a dosagem de antiglicofosfolipídeo-1 (PGL-1). As reações de Montenegro e de Mitsuda e a cultura para fungos e micobactérias de fragmentos da lesão foram também negativas. No exame histopatológico da pele, foi
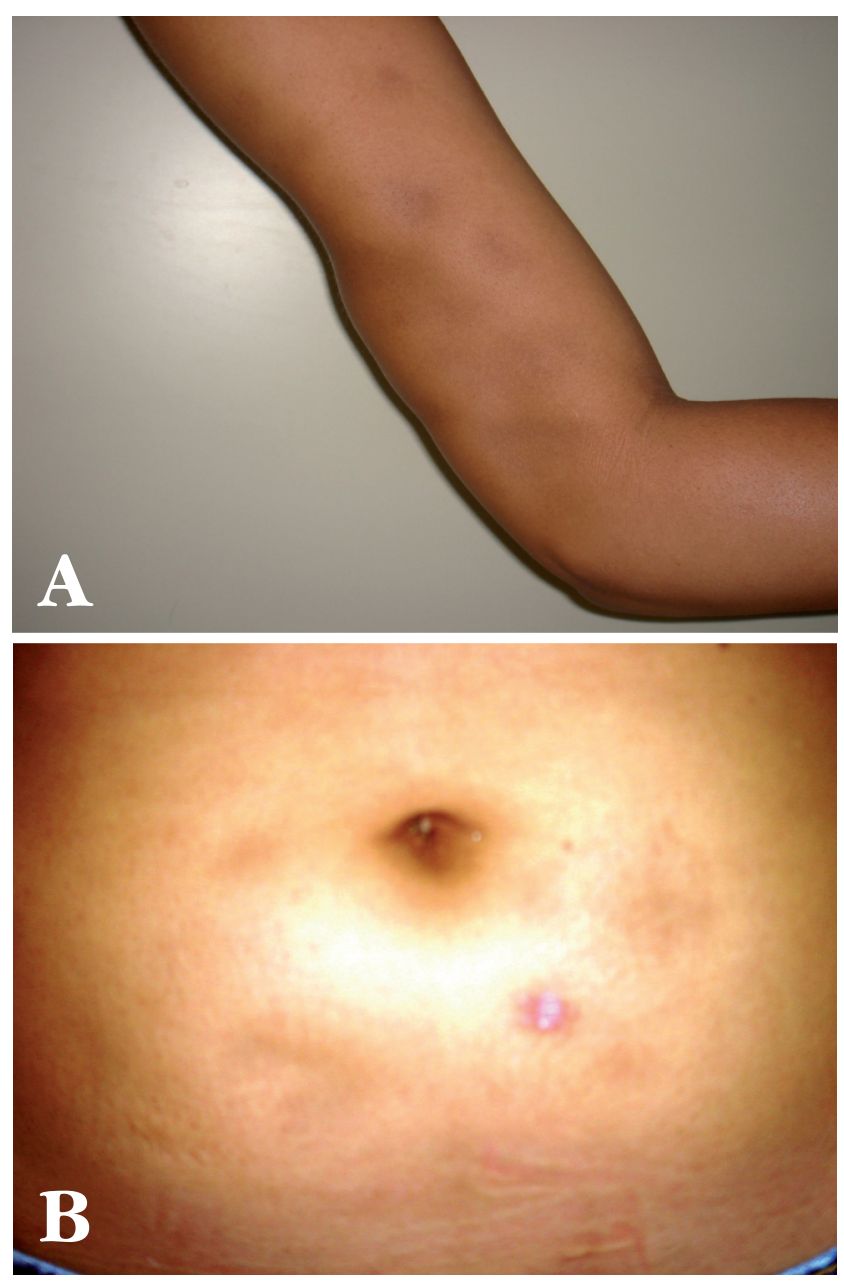

FIGURA 1: Nodosidades eritematosas a violáceas associadas a depressões atróficas no membro superior esquerdo (A); em menor número, no abdome (B)

observado, na derme profunda e tecido celular subcutâneo, denso infiltrado inflamatório linfo-histiocitário composto por frequentes linfócitos atípicos, pequenos a intermediários, dispostos em lençóis que permeavam septos e lóbulos e formavam figuras em anel ao redor dos adipócitos (Figura 1). A imunoistoquímica evidenciou marcação positiva para CD3/CD8 e TIA1 na maioria das células neoplásicas e reação negativa para CD20, CD56 e EBV. Houve coexpressão fraca para CD4 em parte da população de células neoplásicas, e raras células foram positivas para CD30 (Figura 3). As sorologias para HTLV-1, HTLV-2 e EBV foram negativas. A biópsia de medula óssea não demonstrou infiltração medular pelas células neoplásicas. Os exames de tomografia computadorizada da região cervical, torácica e abdominal não identificaram acometimento nodal ou visceral; apenas confirmaram as nodosidades cutâneas no abdome. A paciente foi estadiada como T3NOMO (IIB) e submetida ao esquema CHOP 14, constituído por ciclofosfamida, adriamici- 

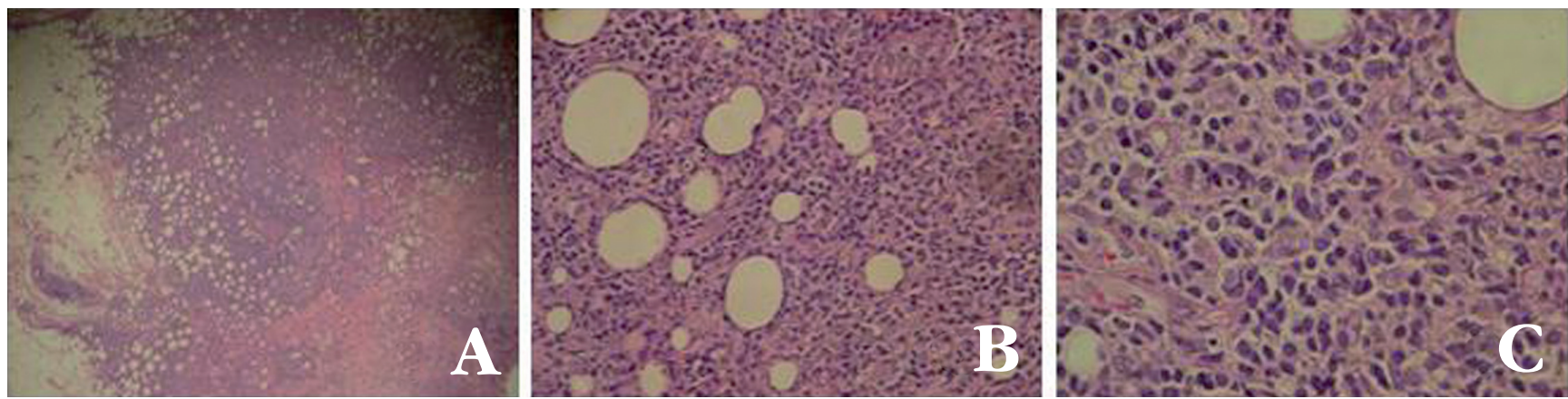

Figura 2: Denso infiltrado inflamatório com frequentes linfócitos atípicos de tamanho pequeno a intermediário na derme profunda e tecido celular subcutâneo (A), dispostos em lençóis que permeiam septos e lóbulos, formando figuras em anel ao redor dos adipócitos (B e C). Hematoxilina-eosina; A $(10 \mathrm{x})$; B (40 x) e C (100 x)
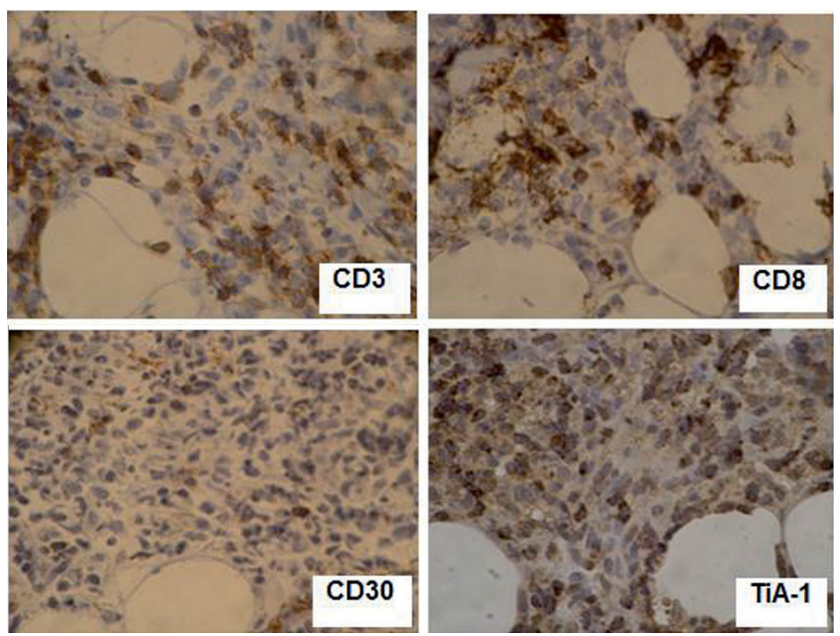

Figura 3: munoistoquímica positiva para CD3, CD8 e TIA-1 na maioria das células neoplásicas. Raras células neoplásicas positivas para CD30.(100 x)

na, vincristina e prednisona, com filgrastima (G-CSF) do quarto ao décimo quarto dia, associado ao metotrexato intratecal antes de cada ciclo da poliquimioterapia. No segundo ciclo, a paciente já negava surgimento de lesões inéditas e referia remissão subjetiva das lesões existentes. Após quatro ciclos de poliquimioterapia, nova biópsia cutânea ainda identificou infiltração de linfócitos atípicos em tecido adiposo subcutâneo com o mesmo padrão imunoistoquímico. A paciente foi então submetida a quatro ciclos adicionais de quimioterapia, completando oito ciclos. Ao final desses ciclos, a interrupção do surgimento de lesões inéditas foi confirmado pelo exame clínico, no qual estavam presentes poucas lesões de aspecto residual associadas às manchas hipercrômicas e depressões atróficas em membros e abdome.

Novos exames de tomografias cervical, torácica e abdominal registraram a ausência de adenomegalia e evidenciaram redução dos diâmetros das nodosidades cutâneas abdominais. A repetição do exame histo- patológico das lesões residuais revelou fibrose no tecido adiposo subcutâneo em região lobular e septal com mínimos focos de infiltrado linfo-histiocitário perivascular sem atipias. A doença foi considerada em remissão, e optou-se pelo seguimento clínico rigoroso da paciente, que já completou oito meses após o término da quimioterapia.

\section{DISCUSSÃO}

O LSCTPS afeta predominantemente adultos jovens, com média de idade ao surgimento aproximadamente duas décadas inferior à média de idade de pacientes com outros tipos de linfoma cutâneo primário de células T, em concordância com o presente caso. Em extensa revisão e análise sistemática de 156 casos registrados na literatura, realizada por Go e Wester em 2004, a média de idade ao diagnóstico foi de 39 anos, variando de 0,5 a 84 anos, sendo que $75 \%$ dos pacientes encontravam-se entre 18 e 60 anos de idade. ${ }^{6}$

Tal revisão congregou relevantes informações acerca da paucidade de casos da literatura. Os autores identificaram: a presença de síndrome hemofagocítica e a expressão do TCR $\gamma \delta$ pelas células tumorais ao diagnóstico estavam associadas a pior prognóstico; a sobrevida média foi de 2 anos; a quimioterapia com derivados da antraciclina ou altas doses de quimioterapia e subsequente transplante de células-tronco estavam entre as opções terapêuticas com os melhores resultados. ${ }^{6-9}$

O encontro de mais de $30 \%$ de células neoplásicas com expressão do TCR $\gamma \delta$ é significativo e consistente com um fenótipo representativo de LSCTPS, uma vez que entre as células T normais essa expressão é de apenas cerca de $7 \%{ }^{5,6}$ Em adição, o rearranjo clonal do TCR foi detectado em $85 \%$ dos pacientes. ${ }^{6}$

A história natural do LSCTPS apresenta com frequência um curso agressivo, resultando em quase $50 \%$ de mortalidade relacionada à doença e sobrevida média de dois anos. O padrão protraído pode ser transitório, habitualmente evoluindo para doença 
mais agressiva. No entanto, pode ser observada uma evolução crônica e indolente, com duração de anos; muito raramente ocorre a remissão espontânea da doença. ${ }^{6}$

Há concordância na literatura acerca da existência de dois grupos de LSCTPS, que poderiam ser diferenciados por seus distintos padrões histológicos, imunofenotípicos e prognósticos. Casos com fenótipo $\alpha \beta$ de células T são usualmente CD8-positivos e restritos ao tecido subcutâneo, sem nenhum envolvimento dérmico ou epidérmico e, frequentemente, com curso clínico indolente. Em contraste, LSCTPSs com fenótipo $\gamma \delta$ das células $\mathrm{T}$ - aproximadamente $25 \%$ dos casos - são tipicamente CD4 e CD8-negativos e usualmente coexpressam CD56. Esse último grupo, cujo infiltrado neoplásico não se confina ao tecido subcutâneo e envolve a derme e a epiderme suprajacente, tem invariavelmente pobre prognóstico. ${ }^{5,6,7}$

No presente caso, o período prolongado de investigação - cerca de três anos - e o diagnóstico prévio distinto exemplificam a dificuldade da elucidação. No entanto, a ausência de manifestações sis- têmicas e de comprometimento nodal e visceral está em concordância com a rara disseminação para sítios extracutâneos registrada na literatura. O caráter menos agressivo e a evolução crônica e indolente parecem compreender a minoria dos casos registrados na literatura, ou consistir em fase transitória da doença. ${ }^{5}$ A despeito do período de cerca de três anos sem tratamento específico, com o estadiamento T3NOM0 (IIB), o tratamento proposto resultou na interrupção do surgimento de lesões inéditas, e apenas fibrose com ausência de linfócitos atípicos foi evidenciada ao exame histopatológico das lesões residuais. No curto tempo de seguimento - oito meses - a remissão da doença tem sido mantida, corroborando o êxito do regime terapêutico baseado na quimioterapia com derivados da antraciclina. Os autores sugerem que a ausência de marcadores de mau prognóstico manteria relação com o padrão da evolução e da resposta terapêutica no presente caso. Ademais, ressaltam a raridade do LSCTPS e a relevância de sua inclusão nos diagnósticos diferenciais da paniculite. 


\section{REFERÊNCIAS}

1. Rosen ST, Querfeld C. Primary cutaneous T-cell lymphomas. Hematology Am Soc Hematol Educ Program. 2006:323-30, 513.

2. Sampaio SAP, Rivitti EA. Leucemias, Linfomas e Pseudolinfomas. In: Sampaio SAP, Rivitti EA, org. Dermatologia. 3 ed. São Paulo:Artes Médicas; 2007. v. 1, 1272 p.

3. Sanches JA, Moricz CZM, Festa Neto C. Processos linfoproliferativos da pele. Parte 2- Linfomas cutâneos de células T e de células NK. An Bras Dermatol. 2006;81:7-25.

4. Kim EJ, Hess S, Richardson SK, Newton S, Showe LC, Benoit BM, et al. Immunopathogenesis and therapy of cutaneous $\mathrm{T}$ cell lymphoma. $\mathrm{J}$ Clin Invest. 2005;115:798-812.

5. Willemze R, Jaffe ES, Burg G, Cerroni L, Berti E, Swerdlow SH, et al. WHO-EORTC classification for cutaneous lymphomas. Blood. 2005;105:3768-85.

6. Go RS, Wester SM. Immunophenotypic and molecular features, clinical outcomes, treatments, and prognostic factors associated with subcutaneous panniculitis-like T-cell lymphoma: a systematic analysis of 156 patients reported in the literature. Cancer. 2004;101:1404-13.

7. Querfeld C, Guitart J, Kuzel TM, Rosen ST. Primary cutaneous lymphomas: a review with current treatment options. Blood Rev. 2003;17:131-42.
8. Querfeld C, Rosen ST, Guitart J, Kuzel TM. The spectrum of cutaneous T-cell lymphomas: new insights into biology and therapy. Curr Opin Hematol. 2005; 12:273-8.

9. Pichardo DA, Querfeld C, Guitart J, Kuzel TM, Rosen ST. Cutaneous T-cell lymphoma: a paradigm for biological therapies. Leuk Lymphoma. 2004;45: 1755-65.

\author{
ENDEREÇO PARA CORRESPONDÊNCIA / MAILING ADDRESS: \\ Profa. Dra. Cacilda da Silva Souza \\ Hospital das Clínicas da Faculdade de Medicina \\ de Ribeirão Preto - USP \\ Av. Bandeirantes, 3900 Monte Alegre \\ 14048900 Ribeirão Preto SP \\ Tel./fax: $163602-2716163633-0236$ \\ e-mail:cssouza@fmrp.usp.br
}

